\title{
Ecological Health Risk of Buriganga River, Dhaka, Bangladesh
}

\author{
Mohd. Yousuf Ali, Md. Nurul Amin and Khairul Alam
}

\begin{abstract}
The efforts of modern civilization to create an environment to meet human aspirations have successfully resulted in constant improvements of our lifestyle, but it has increased risks to human and ecological health. This situation has motivated many scientists throughout the world to analyze the environmental factors that can affect our health or ecology and to calculate the levels of risk. In Bangladesh development activities and utilization of the river pose a great threat to the health of the existing natural environmental system, particularly for the important river Buriganga of the capital city, Dhaka, due to the pollution of the river water.
\end{abstract}

A study was carried out to observe the ecological health hazards of the Buriganga river and their risk to human health. Several random samples of water were collected from different spots on the river from September to December 2006. The samples were analyzed to determine water quality and associated environmental health risks. The study revealed that the water is high in biological oxygen demand (BOD), chemical oxygen demand (COD), phosphate $\left(\mathrm{PO}_{4}^{-3}\right)$, ammonia, organic matters and nutrients, etc. It also revealed huge environmental health risks and possible ecological disruption of this river. Finally, the research recommends a sustainable policy framework on how the pollution could significantly be reduced by using different appropriate measures.

Key words: Environmental health risk, ecological disruption, sustainable policy, water quality, Buriganga river, Bangladesh

\section{Introduction}

R ivers in Bangladesh have been threatened from Rtime immemorial. Indeed, threats date back to the early history of civilization and development. Being a new delta, the courses of rivers are constantly changing. The problems related to Buriganga can be categorized as natural, climate change-related, external to the country, and human made (Alam 1995). In recent years, water quality related issues have surfaced along with water quantity concerns. The river receives a large quantity of wastes (both solid waste and wastewater), surface runoff, untreated industrial effluents and treated sewage effluents directly or indirectly from the city of Dhaka. These wastes contaminate the river water affecting its aquatic life. Analyses of long term data from some of the major rivers in Bangladesh show that the Buriganga is more polluted than any other river in the country (DOE 2000). Most importantly, the quality of the Buriganga river water has been deteriorating. Water quality parameters, such as $\mathrm{pH}$, dissolved oxygen, biological oxygen demand and chlorides hardly satisfy the standards set out by the Bangladeshi Department of Environment (Alam 1995). In addition to the pollution problems, the Buriganga is also under threat of becoming a 'dead' river in the future as the biological diversity as well as other aquatic community including fish is decreasing. Influential people are grabbing the riverbanks resulting in narrowing of the channel. Notwithstanding this, the Buriganga is extremely important for the city of Dhaka. It provides drainage for its internal waters, is a source of drinking water, a place of recreation, and a number of other human activities. As a result, this important river is under great danger due to the enormous threats upon it.
Therefore, to get a vivid scenario in this issue, the Ecological Health Risk of the Buriganga River of Dhaka, Bangladesh has been identified as the study problem.

\section{Materials and Method \\ Sampling technique and station selection}

Water samples were collected randomly from the river at different points. Samples were collected in plastic bottles and their mouths were closed properly. Samples were collected from Station I (i.e., from Pagla point where the water treatment plant is situated), Station II (Hazaribug), Station III (Kamrangir Char) and Station IV (Alam Bazar). Samples were collected at different times from September to December. Each time the water samples were collected from both sides and the mid-point of the river.

\section{Materials used in the field}

Several instruments and chemicals were used, such as a thermometer to determine the temperature, and alkaline iodide, manganese sulphate $\left(\mathrm{MnSO}_{4}\right)$, concentrated sulphuric acid $\left(\mathrm{H}_{2} \mathrm{SO}_{4}\right)$ for fixing dissolved oxygen (DO) were used. Some DO bottles, beakers, pipettes, pipette fillers were used at the site.

\section{Sample analysis and report preparation}

The samples were analyzed for various physicochemical properties with the help of the Environmental Science Discipline Laboratory, Khulna University. Different methods were adopted for various physical and chemical analyses. In the analysis of physicochemical properties of water, standard methods were followed and a number of sophisticated instruments were also used (Ramesh and 
Anbu 1996).

For the interpretation of the environmental health risk the water sample analysis results were compared with the regular river environmental situation. Then some recommendations were made under the light of similar occurrences in other areas around the world.

\section{Results and Discussion}

According to the methodological approaches and data based on the information collected along with secondary literature and information, the research identified the environmental health risks due to the pollution of the Buriganga river. The specific analyses are given below.

\section{River Water Quality and Ecological Health Risks}

A favorable water chemistry is essential for aquatic life, in particular for drinking purposes and environmental health. The chemistry of water influences the life of human beings and environmental health. The rate of birth or death, growth and breeding of fish and human life are dependent on water environmental quality. The fishes can adapt slight changes in water quality but for sudden or extreme changes, fishes may be affected by diseases and ultimately may die.

On the other hand, industries produce heavy loads of wastes that are complex mixtures of many substances including raw products; plastic fiber; partially decomposed organic matters; different chemical substances; inorganic nutrients, particularly nitrogen and phosphorus; and many others. Most of the wastes generated are discharged into the nearby water bodies through discharge channels and are potentially hazardous to the receiving environments.

\section{Temperature}

Both air and water temperatures play important roles in the physicochemical, metabolic and physiological behaviors of the aquatic system. Temperature occupies a central position in limnology; as temperature changes, it affects not only many physiological processes but also, via the density of water, the fundamental stratification of a water body (Tebbutt 1998). During the period of investigation the temperature of the beel (low lying water logged area) water varied from 27 to $29^{\circ} \mathrm{C}$. Average maximum values of water temperature were observed in October and the minimum in November, corresponding to the atmospheric temperature. During October, water temperature was higher because of a low water level, low velocity, clear atmosphere and greater solar radiation.

Temperature may not be an important factor in a non-polluted environment because of the wide range of temperature tolerance of aquatic biota; but in polluted water, rapid temperature changes may cause over shoots in the metabolism of the aquatic organisms and it may have a profound effect on dissolved oxygen and bio-chemical oxygen demand which subsequently affects the aquatic biota, particularly to the fishes of an ecosystem. With increasing water temperature the solubility of oxygen is reduced causing de-oxygenation. Whitton (1979) pointed out that the temperature fluctuates due to the activities of micro-organisms. In summer the decomposition process is faster than in winter and less oxygen is dissolved in warm water so that at a time when more oxygen is required by the organisms, less is available.

In the study it has been observed that the temperature increases slightly in October only at Station I $\left(29^{\circ} \mathrm{C}\right)$ as compared to other stations. It may be due to excess flow of effluents. For Bangladesh, $24^{\circ}$ $28^{\circ} \mathrm{C}$ temperature is standard for aquaculture; however, it is also possible at $22^{\circ}-32^{\circ} \mathrm{C}$ (Nasser 2005). But the problem is that some other parameters may change with temperature rise and fall (Nasser 2005). The fluctuation of temperature of water collected from various stations may interfere in other parameters. Therefore, temperature is one of the great factors for ecological health.

\section{pH value}

The $\mathrm{pH}$ value is an important factor in maintaining the bicarbonate and carbonate system.

The $\mathrm{pH}$ values of beel (low lying water logged area) water at different sampling stations were recorded ranging from 7.1 to 7.9 . Average $\mathrm{pH}$ was 7.56 , 7.35, $7.95,7.29$ in Stations I, II, III and IV respectively (Figure 2). The maximum value of $\mathrm{pH} 8$ was observed in November in Station IV. This rise of $\mathrm{pH}$ might be due to the increased temperature that reduced the solubility of carbon dioxide a factor, which has a bearing on $\mathrm{pH}$. During the study period low values of $\mathrm{pH}$ were observed at Station IV as compared to other stations and higher values at Station III. All the values at the stations for the two months correspond to the standard value; i.e., pH 6-8.5 to World Health Organization (WHO) Standard. So, it may not affect the drinking water quality. This is also not a great factor for other biological lives and ecological health.

\section{Hardness}

The term hardness is frequently used to express the quality of water. In the study, the hardness was induced by significant discharge of polluted industrial effluent and low water level of the river. The values of hardness (calcium and magnesium) vary from 45 to $96 \mathrm{mg} / \mathrm{l}$. Average hardness (calcium and magnesium) was $59.5 \mathrm{mg} / \mathrm{l}, 80.7 \mathrm{mg} / \mathrm{l}, 84.55 \mathrm{mg} / \mathrm{l}, 78.25 \mathrm{mg} / \mathrm{l}$ in Stations I, II, III and IV, respectively.

Calcium ions are important components of plant tissues and participate in various cellular functions. (e.g., calcium pectate is a constituent of cell membrane). It is also required as a nutrient for various metabolic processes and assists in proper 
translocation of carbohydrates that facilitates the availability of other ions (Wetzel 1975).

Magnesium is required universally by chlorophyllous plants as the magnesium porphyrin component of the chlorophyll molecules and as cofactor for various enzymatic transformations within the cell (Wetzel 1975).

\section{Bicarbonate Alkalinity (HCO3-1)}

In the present study, the highest value of bicarbonate was in Station I (372 mg/l) in October. The accumulation of large quantities of bicarbonates may be due to low water level and on account of the presence of excess of free carbon dioxide produced in the process of decomposition (Munawar 1970). High values of bicarbonate of calcium and magnesium were observed in October, when water temperature was high. Average bicarbonate was $366 \mathrm{mg} / \mathrm{l}, 331 \mathrm{mg} / \mathrm{l}$, $327 \mathrm{mg} / \mathrm{l}, 335 \mathrm{mg} / \mathrm{l}$ in Stations I, II, III and IV, respectively.

For aquaculture, $40-200 \mathrm{mg} / \mathrm{l}$ alkalinity is necessary (DOF 2003) which exceeded in various stations. The excess amount may badly affect aquaculture and drinking water. In Buriganga, all the values at the various stations are higher than the optimum range. So, it can adversely affect the aquatic lives and also human health. Therefore, there is a great chance for ecological disruption.

\section{Dissolved Oxygen (DO)}

Dissolved oxygen is one of the most important factors in water quality assessment and reflects the physical and biological processes prevailing in natural water. Its presence is essential to maintain the higher forms of biological life in water.

At all stations quantities of dissolved oxygen were not appreciable. The drinking water must contain 4-6 $\mathrm{mg} / \mathrm{l}$ of DO. But at Stations I, II, III and IV dissolved oxygen saturation level was slightly high. Average DO was $6.1,6.45,6.55,6.4 \mathrm{mg} / \mathrm{l}$ in Stations I, II, III and IV, respectively.

Below $5 \mathrm{mg} / \mathrm{l}$ DO may create a problematic situation for fish biota (DOF 2003). It may be due to the high rate of oxygen consumption by oxidizable matter coming in along with the effluent. Morrissetle and Mavinic (1978) pointed out that decomposition of organic matter was an important factor in consumption of dissolved oxygen, which is more vigorous in warm weather.

The main source of dissolved oxygen is diffusion from the atmosphere and the photosynthetic evolution, Welch (1952) pointed out that under natural conditions, running waters typically contain relatively high concentrations of dissolved oxygen which is rapidly removed from the natural water by the respiration of the biota, decomposition of organic matter, inflow of oxygen deficient wastewater, inorganic reductants such as hydrogen sulphide, ammonia, nitrites, ferrous oxide and other oxidizable substances. Generally, low oxygen concentrations are associated with heavy contamination by organic matter. In such conditions oxygen sometimes, totally disappears from the water. Dissolved oxygen is obviously essential for the metabolism of all aquatic organisms that possess aerobic respiratory biochemistry (Wetzel 1975, Trivedy 1988).

\section{Biological Oxygen Demand (BOD)}

BOD is of great importance in water quality assessment. Seasonal variation in the values of BOD appears to be a function of changes in the degree of dilution, quantity of organic matter and the activities of microorganisms carrying out decomposition of carbonaceous and nitrogenous matters. The BOD values showed high fluctuations primarily due to the addition of effluent of industry and also because of dilution by river water.

\section{Phosphate (PO4-3)}

Ecological interest in phosphorus has arisen because of its major role in biological metabolism and relatively small amounts of phosphorus present in the hydrosphere. Several authors have stressed the importance of phosphates in natural waters (Ohle 1934, Phifer and Thompson 1937). Total phosphate concentration is considered to be a nutrient of major importance in the production process (Hutchinson 1957, Vollenwider 1968). The increased application of fertilizers, use of detergents and domestic sewage greatly contribute to the heavy loads of phosphorus in the water (Golterman 1975).

In the present investigation, the values of phosphate concentration were very high (12 to 39 $\mathrm{mg} / \mathrm{l})$. Average phosphate was 37, 21.5, 17.5, $13 \mathrm{mg} /$ l in stations I, II, III, IV, respectively (Figure 7). The phosphate concentration is high due to excess use of soap, and detergents. Moreover, increased solar radiation that encourages the biological degradation of organic matter and subsequent release of more phosphates and the influx of flood waters rich in phosphates also increases the concentration. In station I the concentration was the highest because it is the nearest to the industry. Values in other stations were lower because of dilution.

\section{Ammonia-nitrogen (NH3-N)}

Un-ionized ammonia is very toxic but the Ammonium ion $\left(\mathrm{NH}_{4}+\right.$ ) is not toxic to fish biota for a water body (Downing and Merkens 1955). According to Inland Fisheries Advisory Commission (1973), if a water body contains only $0.6-2.0 \mathrm{mg} / \mathrm{l} \mathrm{NH}$, it is also toxic to the fish biota. For example, within 96 hours 50 percent Channel catfish died at $3.8 \mathrm{mg} / \mathrm{l} \mathrm{NH} 3$ (Colt et al 1975). Un-ionized $\mathrm{NH}_{3}$ is more toxic to fish when the amount of dissolved oxygen decreases (Downing and Merken 1955). 
In the present investigation, the values of ammonia concentration were very high ( 2.6 to $22 \mathrm{mg} /$ 1) due to rotten material with industrial effluent, fertilizer from surrounding agricultural fields, and the residual parts of fish biota. Average ammonia was 19.5, $11.5,6.5,2.8 \mathrm{mg} / \mathrm{l}$ in Stations I, II, III and IV, respectively.

Where DOF set $0.025 \mathrm{mg} / \mathrm{l}$ ammonia concentration as the upper limit (DOF 2003), 2.8 to $19.5 \mathrm{mg} / \mathrm{l}$ is very toxic to fish biota. Obviously, Ammonia was high in Station I (Figure 8) because of its nearness to industries. In other stations the effluent was diluted with river water. However, these concentrations may destroy the aquatic ecosystem of the river. This evidence is also supported by the presence of Magur and Tilapia fish in this river which were found frequently during site visits

\section{Sustainable policy}

In this situation, initiatives for large scale research are needed to carry out (1) the cleanup of dying rivers, (2) estimating benefits of non-market goods and services, (3) examining the desirability of undertaking the cleanup program for dying rivers, and (4) mobilizing funds from within the community.

The effect of the effluent, however, can be minimized through adoption of possible and potential mitigation measures. The following measures would be helpful in mitigation or avoiding the adverse effects:

- Chemical analysis of samples (Stations I, II, III and IV) shows very high values of the parameters; so, treatment for the total parameters will be more suitable for this study area. Application of simple treatment options such as screening can substantially reduce the waste loads. Screening reduced the BOD load from processing operations by 38\% (Carawan 1991).

- Cleaning up production areas by dry methods before flushing them with water is another way to keep pollutants out of drains. This decrease of $57 \%$ means a further $13 \%$ decrease in the overall BOD load (Szabo et al 1979).

- The very high concentration of ammonia can be reduced by aeration and ion exchange (with Zeolite) (Ramesh and Anbu 1996)

- The government should require periodic reports from industries on measures implemented to protect and improve the environment, especially those industries involved with high environmental and health risks.

\section{Conclusion}

The study definitely supports the probability of environmental health risks in the study area. Tentative causes to support ecological degradation in the Buriganga river area are due to the lack of pollution preventing activities. From the study, it is almost certain that the environmental health risk due to water pollution is at a stage in the area that will definitely affect us in the days to come.

Mohd Yousuf Ali is Assistant Professor of Fisheries and Marine Resource Technology of Khulna University, Bangladesh. Md Nurul Amin and Khairul Alam are MS graduates in the same institution.

Corresponding address: yousufku@gmail.com 